\title{
Estimation of Liquid Water Amount in an Extended Cloud by Nimbus-5 Microwave Data
}

\author{
By Takao Takeda and Shohei Natsuki* \\ Water Research Institute, Nagoya University; Nagoya 464, Japan \\ (Manuscript received 24 March 1982, in revised form 20 August 1982)
}

\begin{abstract}
The possibility of estimating liquid water amount in the atmosphere from satellite microwave data was studied numerically by making use of a cloud model in which the size distribution of water drops and other factors were varied, and integrated liquid water amount in an extended cloud over the AMTEX area was estimated by using Nimbus- 5 microwave data at $19.35 \mathrm{GHz}$ (ESMR). Numerical calculations show that integrated liquid water amount can be estimated from satellite microwave data with the error less than $10 \%$ even in consideration of the effect of different size distribution of water drops on estimated value, if it is less than $0.30 \mathrm{~g} / \mathrm{cm}^{2}$. In the atmosphere over the AMTEX area integrated liquid water amount was smaller than $0.12 \mathrm{~g} / \mathrm{cm}^{2}$ during the period of cold-air outbreak from the Asian Continent (Feb. 25 to 27 in 1974). It was smaller than $0.03 \mathrm{~g} / \mathrm{cm}^{2}$ in the system composed of only low-level clouds and it was between 0.05 and $0.12 \mathrm{~g} / \mathrm{cm}^{2}$ in the two-layers cloud system composed of low-level clouds and middle-level clouds. The rate of conversion of cloud water into rainwater in an extended cloud was discussed on the basis of integrated liquid water amount derived from satellite microwave data and rainfall intensity measured on the ground.
\end{abstract}

\section{Introduction}

The estimation of liquid water amount in an extended cloud system, specially by a remotesensing method, has been desired in the study of the formation of precipitation in the cloud system. A radar is an instrument which is favorable for studying precipitation phenomena. But generally it can detect only relatively large drops because of the adopted wave-length of electromagnetic wave. It is very difficult to estimate the amount of cloud water composed of droplets smaller than $100 \mu \mathrm{m}$ in radius by radars. A laser radar also is not suitable for measuring the amount of cloud water because of the large attenuation of electromagnetic wave by water droplets.

Fortunately microwave radiometers or spectrometers have been set in satellites of Nimbus-5, Nimbus-6, Nimbus-7 and Seasat. They give us the possibility of estimating the amount of liquid water, which includes both cloud water and rainwater, in the atmosphere. Staelin et al. (1976)

\footnotetext{
* Present affiliation: Fujitsu Limited.
}

estimated the amounts of water vapor and liquid water in the atmosphere on the global scale, using the data of Nimbus-E Microwave Spectrometer (NEMS), and Allison et al. (1974) made the preliminary estimation of rainfall in a tropical cyclone on the basis of the data of Nimbus-5 Electrically Scanning Microwave Radiometer (ESMR) and Temperature Humidity Infrared Radiometer (THIR). Grody et al. (1980) also derived the amounts of water vapor and liquid water over the tropical Pacific Ocean from the data of Nimbus-6 Scanning Microwave Spectrometer (SCAMS).

So far the estimation of liquid water amount based on satellite microwave data has been discussed mainly for clouds containing only small droplets. Staelin (1966) studied the absorption of microwave in clouds composed of droplets which is very small as compared with its wavelength. Wilheit (1972) discussed the relationship between brightness temperature determined from received microwave and the amounts of water vapor and liquid water on the assumption that the atmosphere is composed of non-scattering medium. It is well known, however, that water 
drops in the atmosphere have a considerably wide range of radius from a few $\mu \mathrm{m}$ to $3000 \mu \mathrm{m}$ and large drops scatter microwave to a large extent. Although Wilheit et al. (1977) and Tsang et al. (1977) calculated the microwave radiation of water drops in consideration of scattering due to them, the model of clouds and the size distribution of water drops assumed in their calculation were rather simple.

When satellite microwave data is applied to the estimation of liquid water amount, it will be necessary to take into account the size distribution of water drops, the types of a cloud and rain and atmospheric conditions. In this paper we attempt to estimate liquid water amount for different kinds of cloud systems over the area, where Air Mass Transformation Experiment (AMTEX) was made in 1974, using Nimbus-5 microwave data (ESMR) at the frequency of 19.35 GHz. First we will discuss the reasonability of liquid water amount estimated from satellite microwave data of $19.35 \mathrm{GHz}$ on the basis of a model in which both the size distribution of water drops and the type of a cloud are varied.

\section{Effects of the size distribution of water drops and other factors on the estimation of liquid water amount}

The microwave emissivity of land surface is typically 0.8 to 1.0 , and the emissivity of sea surface is around 0.4 though it is much dependent upon the roughness of sea surface. It is difficult to estimate accurately liquid water amount in the atmosphere over the land because of the high emissivity of land surface. However, the ocean usually shows brightness temperature much lower than clouds as a result of its low emissivity and it has no remarkable influence on estimated liquid water amount as a background value.

Main radiators in the atmosphere at the frequency of about $20 \mathrm{GHz}$ are water vapor and water drops. Ice is regarded to be essentially transparent at this frequency. While water vapor and water drops in the atmosphere absorb and scatter microwave radiated from the ocean, they emit microwave more intensive than emitted by the ocean. If we can exclude the contribution of water vapor from microwave received by a satellite radiometer, the contribution of water drops can be derived and net radiation from clouds can be estimated. The theory of Mie scattering indicates that when the radii of water drops in clouds are sufficiently small in comparison with the wave-length of microwave, the net radiation from clouds is not dependent upon the size distribution of drops in spite of scattering due to drops. But it might not be reasonable to neglect the influence of the size distribution of drops on the estimation of liquid water amount for precipitating clouds which contain large drops.

In this section we will discuss the influence of the size distribution of water drops, cloud depth and the vertical distribution of liquid water content on the estimation of liquid water amount on the basis of numerical calculations for some cloud-models. We apply the discrete ordinate method of Liou (1973) to numerical calculations.

\section{1) Equations}

Radiative transfer equation of microwave can be written for the axially symmetric and scattering atmosphere by using the Rayleigh-Jeans approximation as follows:

$$
\begin{aligned}
& \frac{d T_{B}(Z, \theta)}{d Z}+\gamma_{\mathrm{ext}} T_{B}(Z, \theta) \\
& \quad=\frac{\gamma_{\mathrm{scat}}}{2} \int_{0}^{\pi} P\left(\theta, \theta_{s}\right) T_{B}\left(Z, \theta_{s}\right) \sin \theta_{s} d \theta_{s} \\
& +\gamma_{\mathrm{abs}} T(Z) .
\end{aligned}
$$

Here, $T_{B}(Z, \theta)$ is brightness temperature in the direction specified by angle $\theta, \theta_{s}$ zenith angle of incident radiation, $\gamma$ ext extinction coefficient, $\gamma_{\text {scat }}$ scattering coefficient, $\gamma_{\text {abs }}$ absorption coefficient, $P\left(\theta, \theta_{s}\right)$ a normalized phase function and $T(Z)$ the thermodynamic temperature of the atmosphere.

The extinction cross section $\sigma_{\text {ext }}$ and the scattering cross section $\sigma_{\text {scat }}$ of a water drop are given by

$$
\begin{aligned}
& \sigma_{\text {ext }}=\frac{\lambda^{2}}{2 \pi} R_{e} \sum_{n=1}^{\infty}(2 n+1)\left(a_{n}+b_{n}\right) \\
& \sigma_{\text {scat }}=\frac{\lambda^{2}}{2 \pi} \sum_{n=1}^{\infty}(2 n+1)\left(\left|a_{n}\right|^{2}+\left|b_{n}\right|^{2}\right)
\end{aligned}
$$

where $\lambda$ is the wave-length of microwave, and $a_{n}$ and $b_{n}$ are electric and magnetic $2^{n}$ pole coefficients, respectively. The volume extinction and scattering coefficients of water drops can be related to the extinction and scattering cross sections as follows;

$$
\begin{aligned}
& \gamma_{\text {ext }}=\int_{r_{\min }}^{r_{\max }} n(r) \sigma_{\mathrm{ext}} d r \\
& \gamma_{\text {scat }}=\int_{r_{\text {min }}}^{r_{\max }} n(r) \sigma_{\text {scat }} d r
\end{aligned}
$$


where $n(r)$ is the number density function of water drops of radius $r$. Coefficients $a_{n}$ and $b_{n}$ are dependent upon the wave-length of microwave, the radius of a water drop and the index of refraction of water. We obtained the values of coefficients $a_{n}$ and $b_{n}$ by applying Ray's formula (1972) to the calculation of complex refractivity.

2) Size distribution of water drops and cloud model adopted in calculation

As well known, the size distributions of cloud droplets and raindrops are largely dependent upon the type of a cloud, its developing stage and the location in it. Generally the size distribution of cloud droplets can be approximated by a Gaussian distribution (Warner, 1969) and that of raindrops can be expressed by an exponential distribution (Srivastava, 1971). We adopted the size distributions of water drops which are given by following formulae based on the observed features of cloud droplets and raindrops;

$$
\begin{array}{ll}
n(r)=n_{1} \exp \left(-a(r-5)^{2}\right) & 5 \leqq r<40 \mu \mathrm{m} \\
n(r)=n_{2} \exp (-b(r-40)) & 40 \leqq r<100 \mu \mathrm{m} \\
n(r)=n_{3} \exp (-c(r-100)) & 100 \leqq r \leqq 2000 \mu \mathrm{m},
\end{array}
$$

where $n(r) d r$ is the number density of water drops of $r$ to $r+d r$ in radius. The size distribution of water drops is expressed by 34 discrete radii from $5 \mu \mathrm{m}$ to $2000 \mu \mathrm{m}$ in calculation.

Three kinds of cloud models are shown in Fig. 1. In models $A$ and $B$ a cloud is composed of cloud droplets and raindrops uniformly through the whole cloud layer, but in model $\mathrm{C}$ there are three layers-a layer composed of only

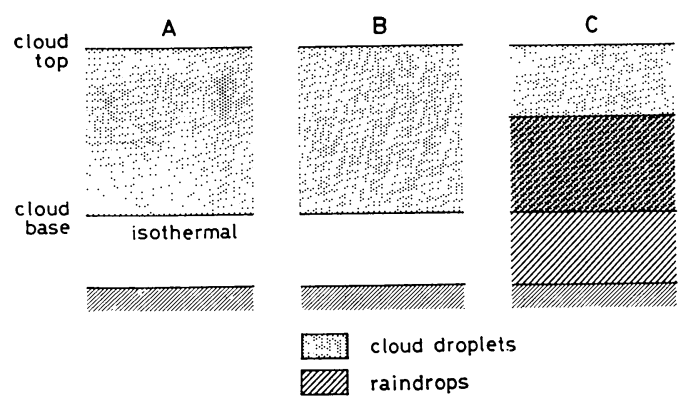

Fig. 1 Three kinds of cloud models adopted in numerical calculation. cloud droplets, a layer composed of cloud droplets and raindrops and a layer including only raindrops. In model $\mathrm{A}$ the atmosphere is assumed to be isothermal, but in models $\mathrm{B}$ and $\mathrm{C}$ air temperature decreases with height.

3) Results of calculation

In calculation the wave-length of microwave is assumed to be $1.55 \mathrm{~cm}(19.35 \mathrm{GHz}$ in frequency). The theory of Mie scattering indicates that if the radii of drops are smaller than $100 \mu \mathrm{m}$, the effect of scattering due to drops can be neglected for radiative transfer of microwave of this wave-length. In all of following cases the brightness temperature of the sea surface is $130 \mathrm{~K}$ and the value of $\theta$ is $70^{\circ}$.

Brightness temperatures calculated by three methods for the cloud-model B are shown in Fig. 2. In method $a$ the effect of scattering due to drops is included in radiative transfer equation and the size distribution of drops is taken into account. In method $b$ the effect of scattering is neglected, but the effect of drop size distribution on an absorption coefficient is taken into account. In method $c$ the effect of scattering is neglected, and an absorption coefficient given by Staelin (1966), in which drop size distribution is not taken into account, is adopted. Abscissa is liquid water amount which was integrated vertically in the atmospheric column of unit horizontal area (hereafter it will be called "integrated liquid water $\bar{L}$ "). In this cloud model the larger is integrated liquid water, the greater number of large drops are included. Ordinate

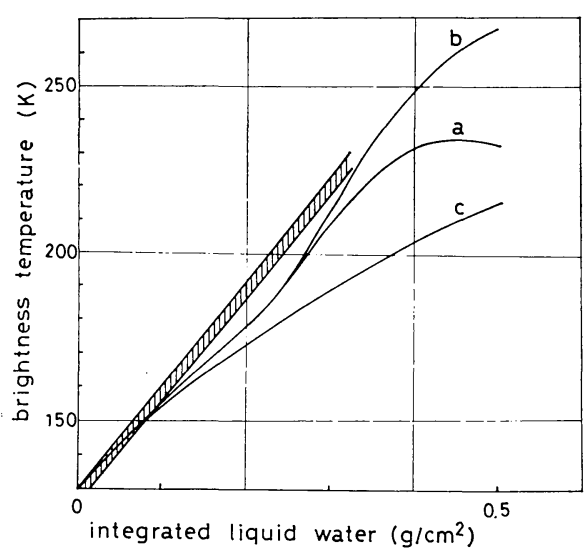

Fig. 2 Brightness temperatures calculated by three methods which are described in text. Shaded area indicates the relationship obtained by the formula of Wilheit (1972). 
is a calculated brightness temperature. There is no difference among brightness temperatures calculated by three methods for integrated liquid water less than $0.10 \mathrm{~g} / \mathrm{cm}^{2}$. But the size distribution of drops has a significant effect on brightness temperature for water amount larger than $0.10 \mathrm{~g} / \mathrm{cm}^{2}$ and the effect of scattering also becomes significant for water amount larger than $0.25 \mathrm{~g} / \mathrm{cm}^{2}$. This result means that even if integrated liquid water is the same, three methods give significantly different values to brightness temperature when integrated liquid water is large.

In order to study the influence of the different size distribution of drops in detail, we calculated brightness temperatures for various size distributions using the cloud-model A. The effect of scattering is included in radiative transfer equation. The results of calculation are shown in Fig. 3. For each line the size distribution of drops smaller than $100 \mu \mathrm{m}$ in radius is the same and the contribution of larger drops, in the radius range from $100 \mu \mathrm{m}$ to $2000 \mu \mathrm{m}$, to liquid water content increases with integrated liquid water (each solid line in Figs. 4, 5 and 6 shows the similar variation of drop size distribution with integrated liquid water). Liquid water in an upper line is composed of a greater number of small drops and a smaller number of large drops than that in a lower line. In the range of integrated liquid water amount from 0.18 to $0.25 \mathrm{~g}$ / $\mathrm{cm}^{2}$ calculated brightness temperature is higher for the same water amount, if liquid water is composed of a greater number of small drops and a smaller number of large drops. Above $0.25 \mathrm{~g} / \mathrm{cm}^{2}$ calculated brightness temperatures are much different for the same integrated liquid

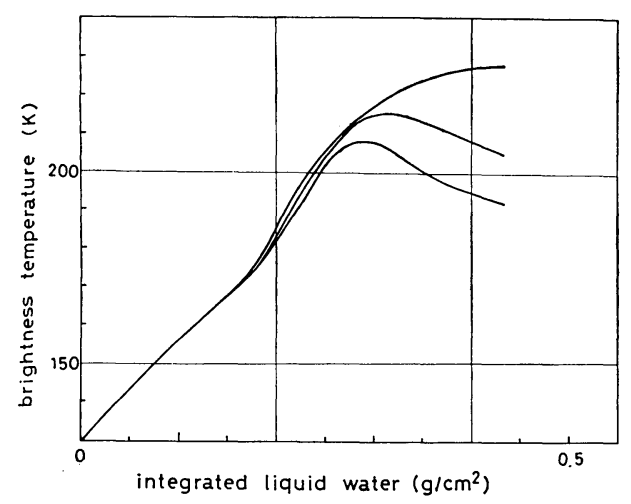

Fig. 3 Effect of different size distribution of water drops on brightness temperature. water if the size distribution of drops is different. But we can say that integrated liquid water less than $0.30 \mathrm{~g} / \mathrm{cm}^{2}$ can be estimated from brightness temperature with the error less than $10 \%$. The estimation of integrated liquid water larger than $0.35 \mathrm{~g} / \mathrm{cm}^{2}$ would not be valid due to the effect of multiple scattering caused mainly by large drops.

The scattering and extinction coefficients of drops are not dependent largely on air temperature. It is expected that the different vertical profile of air temperature does not cause significantly different brightness temperature for the

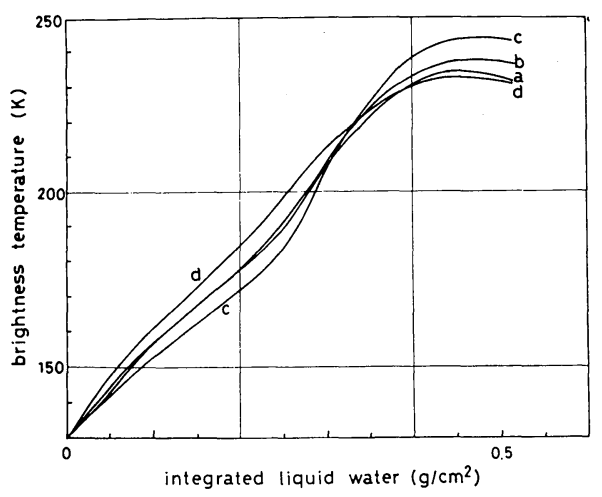

Fig. 4 Effect of different air temperature in the cloud layer on brightness temperature. Cases a, b, c and d are described in text.

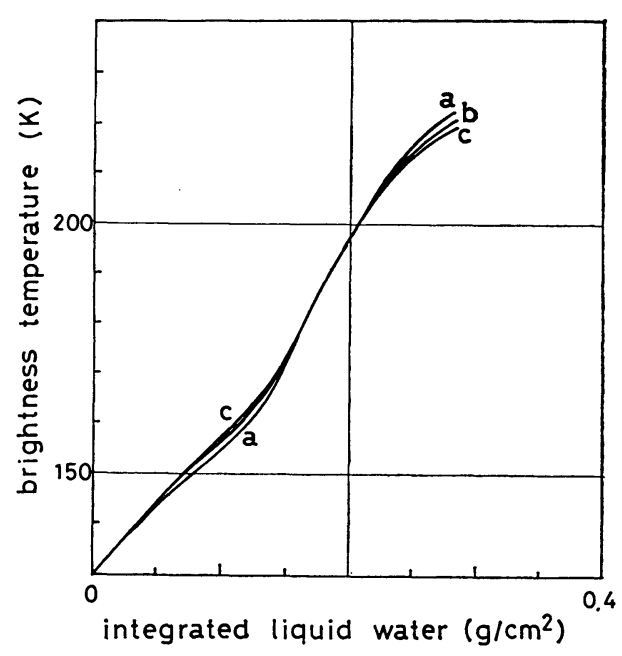

Fig. 5 Effect of different vertical profile of liquid water content $L$ on brightness temperature. (a); $d L / d Z<0$; (b); $d L /$ $d Z=0$ and (c); $d L / d Z>0$. 
same integrated liquid water. The effect of different air temperature in the cloud layer on brightness temperature is shown in Fig. 4. In all of cases $a, b, c$ and $d$ cloud depth is $3000 \mathrm{~m}$ and the same type of drop size distribution is adopted. In case $a$ the cloud model $B$ is used and the lapse rate of temperature is $0.6 \mathrm{C} / 100 \mathrm{~m}$. Temperatures at cloud base and cloud top are $15 \mathrm{C}$ and $-3 \mathrm{C}$, and temperature averaged through the cloud layer is $6 \mathrm{C}$. In cases $b, c$ and $d$ an isothermal cloud (model $\mathrm{A}$ ) is assumed and the cloud layer has constant temperatures of 6,15 and $-3 \mathrm{C}$, respectively.

The relationship between brightness temperature and integrated liquid water in case $a$ shows a good agreement with that in case $b$. This implies that brightness temperature is not dependent on the vertical profile of air temperature and its dependency on a representative temperature of the cloud layer can be approximated by the dependency on the averaged temperature. Fig. 4 shows that the relationship between brightness temperature and the averaged temperature for integrated liquid water less than $0.3 \mathrm{~g} / \mathrm{cm}^{2}$ is qualitatively different from that for liquid water larger than $0.3 \mathrm{~g} / \mathrm{cm}^{2}$. This difference occurs mainly because the temperature dependencies of absorption and scattering coefficients of drops vary with the size of drops. When the averaged temperature of the cloud layer increases, drops smaller than $500 \mu \mathrm{m}$ in radius tend to reduce brightness temperature of the cloud though large drops of about $1000 \mu \mathrm{m}$ tend to increase brightness temperature. In the cloud of integrated liquid water less than $0.3 \mathrm{~g} / \mathrm{cm}^{2}$, the contribution of small drops to liquid water is large, and

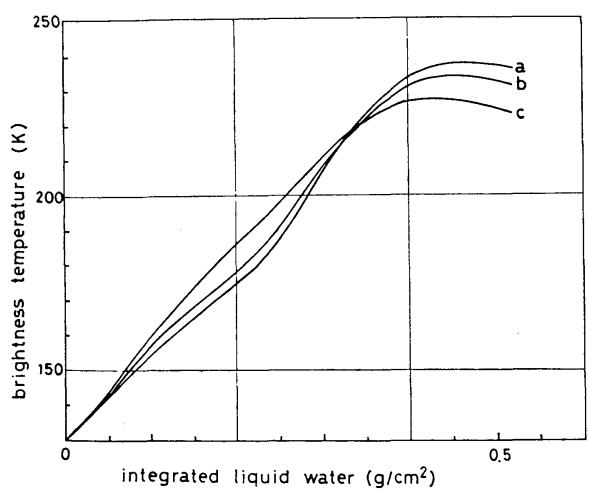

Fig. 6 Effect of different cloud depth on brightness temperature. (a); $1500 \mathrm{~m}$, (b); $3000 \mathrm{~m}$ and (c); $6000 \mathrm{~m}$. brightness temperature decreases with the increasing averaged temperature in association with the temperature dependencies of absorption and scattering coefficients of small drops. In the cloud larger than $0.3 \mathrm{~g} / \mathrm{cm}^{2}$ in integrated liquid water large drops show a large contribution to liquid water and the temperature dependencies of their coefficients have an influence on the relationship between brightness temperature and the averaged temperature of the cloud. But it can be said from Fig. 4 that different averaged temperature of the cloud layer has no large effect on brightness temperature if integrated liquid water is the same.

In the real atmosphere liquid water is not distributed uniformly in the cloud layer. The effect of different vertical profile of liquid water content $L$ on brightness temperature is shown in Fig. 5. The cloud-model $\mathbf{B}$ is adopted and cloud depth is $3000 \mathrm{~m}$ in any case. Temperatures at cloud base and cloud top are $15 \mathrm{C}$ and $-3 \mathrm{C}$. If integrated liquid water is the same and the vertical profile of temperature is the same, brightness temperature hardly depends upon the vertical profile of liquid water content.

It is seen in Fig. 6 that the variation of cloud depth also has little influence on brightness temperature for the same integrated liquid water. The cloud-model $\mathrm{B}$ is adopted in Fig. 6. When integrated liquid water is the same, the same type of drop size distribution is used and only the number density of drops decreases with cloud depth. Fig. 6 shows that a deeper cloud has higher brightness temperature when integrated liquid water is small, and it has lower brightness temperature for large integrated liquid water. Since the temperature dependencies of absorption and scattering coefficients of drops vary with the size of drops, they have an influence on the relationship between brightness temperature and cloud depth. The influence is rather complicated dependently upon integrated liquid water (in other words, drop size distribution) similarly to the result shown in Fig. 4. But we can say that the effect of cloud depth on brightness temperature is not large in comparison with the dependency of brightness temperature on integrated liquid water.

As inferred from results in Figs. 4, 5 and 6, the brightness temperature of a cloud is hardly dependent upon at what levels raindrops exist in the cloud layer. The difference between cloudmodels $B$ and $C$ shown in Fig. 1 has little effect 
on brightness temperature.

Usually sea surface does not disturb the estimation of liquid water amount in the atmosphere as a background because its brightness temperature is low in the wave-length range of microwave considered here. However, microwave emissivity has a tendency to increase with the roughness of sea surface which is related to wave, spray and foam (Hollinger, 1972; Nordberg et al., 1971). Rosenkranz and Staelin (1972) and Stogryn (1967) also discussed the effect of the spray and wave of sea surface on microwave emission theoretically. When we estimate liquid water amount over the ocean by making use of satellite microwave data, the effect of the roughness of sea surface on brightness temperature should be taken into account in the situation of strong wind. The formation of wave, spray and foam generally depends upon the strength of wind above sea surface. Nordberg et al. (1971) obtained the relationship between microwave emission from sea surface and wind velocity on the basis of aircraft observations. They stated that the increase in brightness temperature with wind velocity was negligibly small in the situation of wind weaker than $7 \mathrm{~m} /$ sec, but its increasing rate reached about $1.2 \mathrm{~K} /$ $\mathrm{m} / \mathrm{sec}$ in the case of wind stronger than $7 \mathrm{~m} / \mathrm{sec}$.

\section{Estimation of integrated liquid water over AMTEX area}

Nimbus-5 ESMR gives us the intensity of microwave at $19.35 \mathrm{GHz}$ radiated from the atmosphere and the earth surface. Its resolution is $25 \mathrm{~km}$ at sub-satellite point. The measurement of ESMR was made at about 12:00 JST and 24:00 JST around Japan. As the area for analysis we selected the area of about $10^{6} \mathrm{~km}^{2}$ shown in Fig. 7, where Air Mass Transformation Experiment (AMTEX) was performed from Feb. 14 to 28 in 1974, because many meteorological data were obtained by radio-sondes, radars, observational ships and raingauges in this experiment.

As mentioned in the previous section, integrated liquid water can be estimated reasonably from satellite microwave data if it is less than $0.30 \mathrm{~g} / \mathrm{cm}^{2}$. Firstly we estimated integrated liquid water using the formula given by Wilheit (1972) $-T_{B}=A+B \bar{V}+C \bar{L}$, where $\mathrm{A}$ is the contribution of sea surface. The amount of integrated water vapor $\bar{V}$ was estimated from upper air sounding data in AMTEX area and its contribution to brightness temperature was excluded

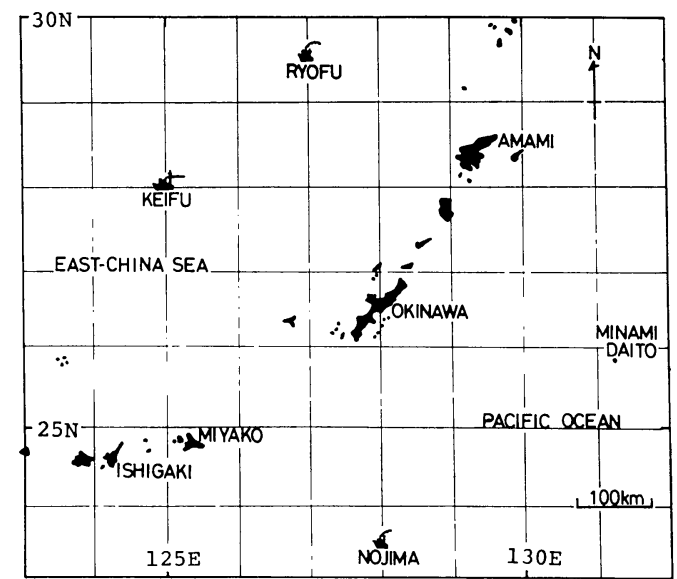

Fig. 7 AMTEX area adopted for analysis.

in determining integrated liquid water. The relationship between brightness temperature and integrated liquid water, which is determined directly from the formula of Wilheit for the brightness temperature of sea surface of $125 \mathrm{~K}$ to $130 \mathrm{~K}$, is shown in Fig. 2. When wind velocity near sea surface was larger than $7 \mathrm{~m} / \mathrm{sec}$, integrated liquid water was corrected on the basis of the increasing rate of brightness temperature obtained by Nordberg et al. (1971). If integrated liquid water was larger than $0.1 \mathrm{~g} / \mathrm{cm}^{2}$, we corrected it by taking into account the effect of drop size distribution discussed before. This method of estimation based on one wave-length measurement would not be applicable when the upper air sounding data of water vapor amount are not usable.

Fig. 8 indicates the horizontal distribution of integrated liquid water over the AMTEX area. The region near Okinawa Island and Amamioshima Island was excluded from analysis, because water amount could not be estimated reasonably in this region as a result of the high brightness temperature of the land. Water amount is larger than $0.06 \mathrm{~g} / \mathrm{cm}^{2}$ in shaded area of Fig. 8. The maximum value of water amount is about $0.12 \mathrm{~g} / \mathrm{cm}^{2}$.

The outbreak of cold air from the Asian Continent occurred during the period of Feb. 25 to 27 in 1974. It can be seen from the cloud picture in Fig. 9 that on Feb. 26 the northern and southern parts of the AMTEX area were covered with cellular clouds and rather uniform clouds, respectively. The comparison of Fig. $8 \mathrm{~b}$ with Fig. 9 reveals that the different value of integrated liquid water seems to reflect roughly the 

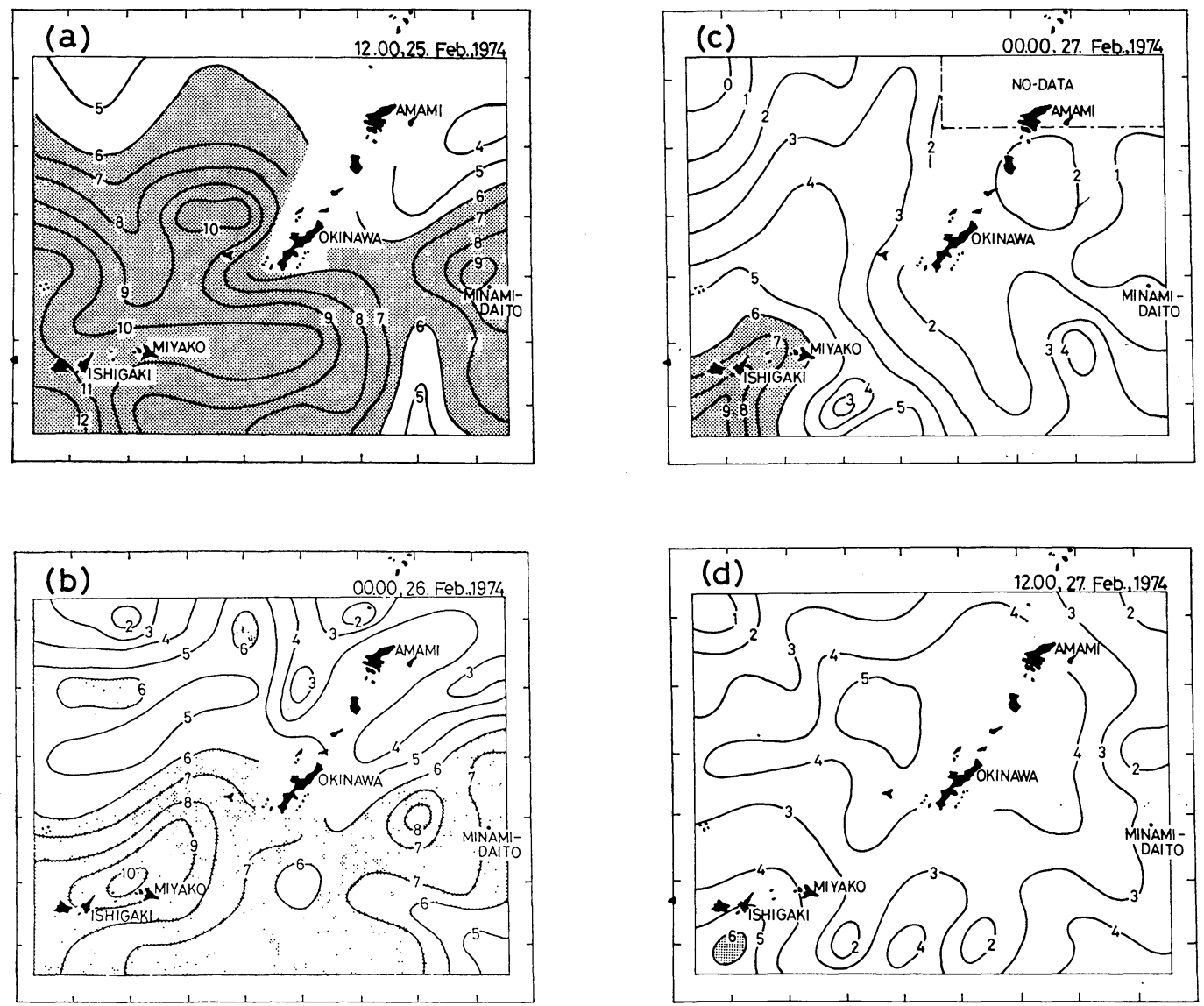

Fig. 8 Horizontal distributions of integrated liquid water amount $\left(\times 10^{-2} \mathrm{~g} / \mathrm{cm}^{2}\right)$.

difference in cloud type over the AMTEX area.

We estimated the depth of a cloud layer over the AMTEX area using upper air sounding data which were obtained at meteorological stations and observational ships. Here the cloud layer is defined to be the layer of relative humidity larger than $90 \%$. Cloud layers in a non-shaded area of Fig. 8 are shown in Fig. 10. Since rainfall was not observed below these cloud layers, integrated liquid water would be nearly equal to the amount of integrated cloud water $\bar{m}$ which is defined as follows;

$$
\bar{m}=\int_{h}^{H} m d z \text {. }
$$

Here $m$ is cloud water content composed of water drops smaller than $100 \mu \mathrm{m}$ in radius, $H$ and $h$ are the heights of cloud top and cloud base.

Cloud layers in a shaded area of Fig. 8 are shown in Fig. 11. They extended up to middle levels. Precipitation was observed below these cloud layers and hourly rainfall amount was less than $1.0 \mathrm{~mm}$. Takeda et al. (1979) pointed out that over the southern part of the AMTEX area precipitation resulted from a two-layers cloud system during the period of cold-air outbreak. Vertical profiles of equivalent potential temperature $\theta_{e}$ and relative humidity shown in Fig. 12 suggest that vertical air motions at low levels and at middle levels were separated by a stable layer. Similar vertical profiles of $\theta_{e}$ and relative humidity were observed at other stations. Surely the southern part of the AMTEX area in Fig. 8 was covered with the two-layers cloud system on Feb. 25 and 26, even if relative humidity was larger than $90 \%$ through the layer from low-level to middle-level.

Generally integrated liquid water derived from satellite microwave data is the sum of rainwater amount and cloud water amount which were integrated from the earth surface and cloud base upward, respectively; 


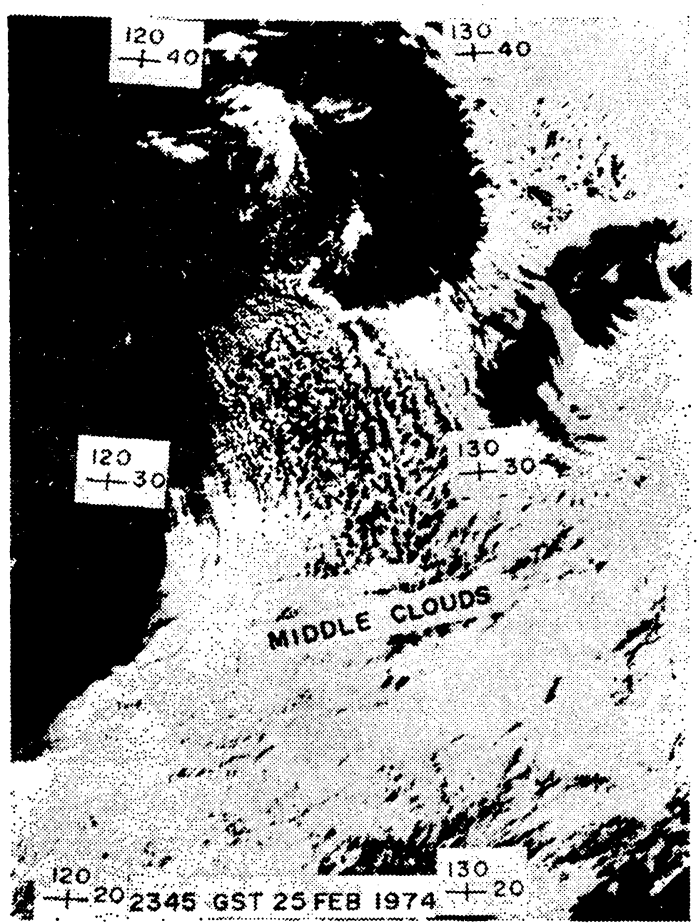

Fig. 9 Cloud picture of DMSP satellite at 8:45 JST on Feb. 26 in 1974 (Ninomiya, 1975).
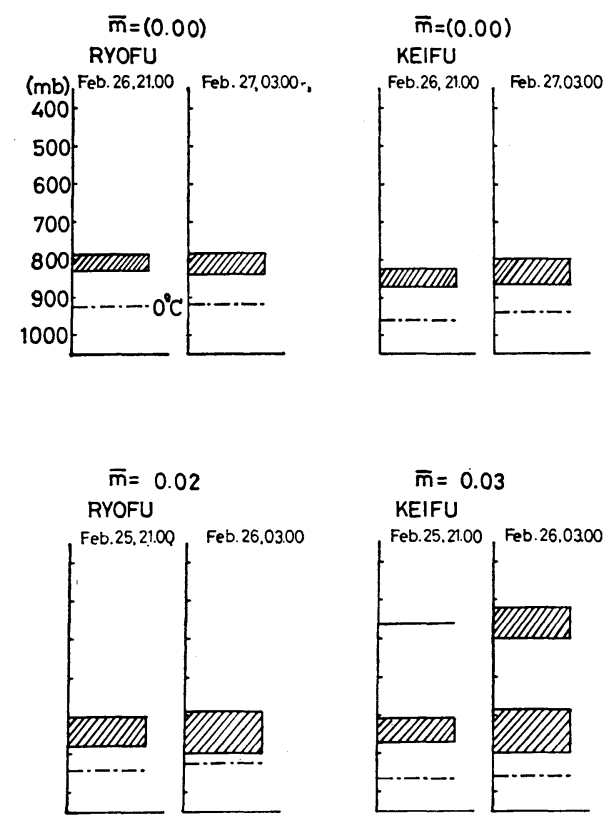

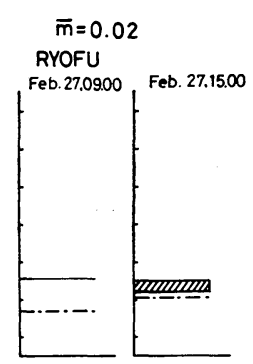

Fig. 10 Cloud layers over the AMTEX area where integrated liquid water is smaller than $0.06 \mathrm{~g} / \mathrm{cm}^{2}$. The values of $\bar{m}$ shows integrated cloud water amount. 

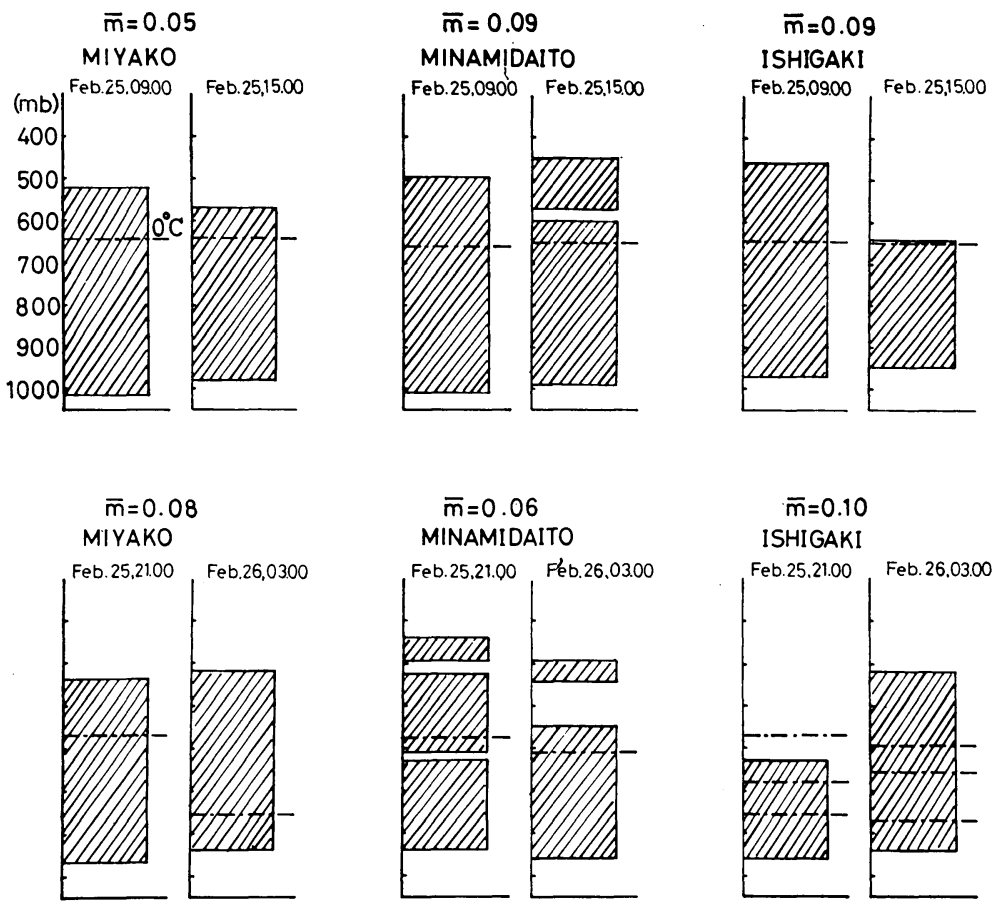

Fig. 11 Cloud layers over the AMTEX area where integrated liquid water is larger than $0.06 \mathrm{~g} / \mathrm{cm}^{2}$.

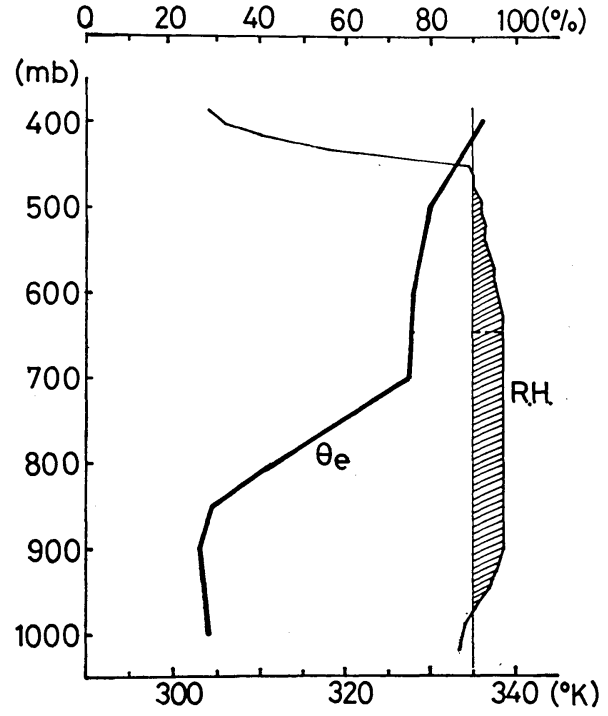

Fig. 12 Vertical profiles of equivalent potential temperature $\theta_{e}$ and relative humidity at Ishigaki Island at 9:00 JST on Feb. 25 in 1974.

follows. In the case of only low-level clouds they were less than $0.03 \mathrm{~g} / \mathrm{cm}^{2}$. Integrated cloud water amounts were estimated hypothetically as

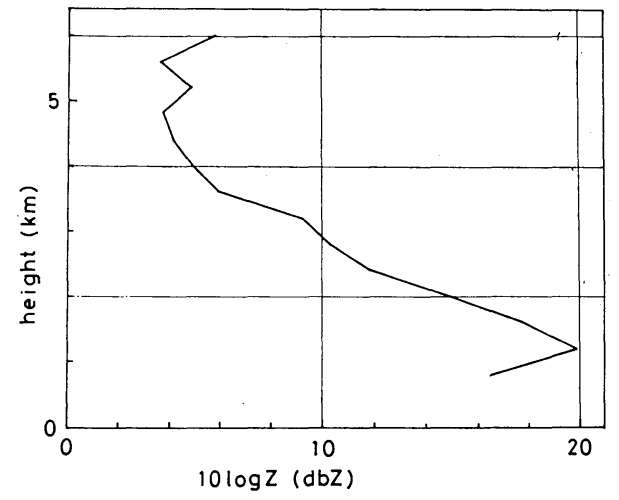

Fig. 13 Vertical profile of radar reflectivity factor observed at Miyako Island during the period of 11:00 to $12: 00$ on Feb. 25 in 1974.

released in air parcels which ascended moistadiabatically on the atmospheric condition in the northern AMTEX area. The values of integrated cloud water amounts estimated by these two methods were not so different. In the case of two-layer cloud systems the amount of integrated cloud water was 0.05 to $0.10 \mathrm{~g} / \mathrm{cm}^{2}$. These values were nearly half as much as hypothetical cloud water amounts inferred from air parcels, 
which ascended moistadiabatically up to the top of middle-level clouds on the atmospheric condition in the southern AMTEX area. This result might occur partly because ice water contained in middle-level clouds is not able to be estimated from satellite microwave data reasonably.

\section{Discussion on the rate of conversion of cloud water into rainwater}

In a precipitating cloud cloud-water is converted into rainwater through the growth processes of precipitation particles. A conversion rate is dependent upon microphysical processes and factors, and it would be much different among clouds. Berry (1968) and Cotton (1970) proposed the conversion rate ("auto-conversion rate"), whose physical meaning is a little different from the above-mentioned rate, from the viewpoint of microphysics. The conversion rate, which is evaluated as a whole in an extended cloud, is an important parameter in the understanding of the formation of precipitation in the cloud. The estimation of the conversion rate has been attempted, but the rate remains uncertain.

Although the conversion rate is complicatedly related to many processes and factors, it can be defined as a rough approximation as follows;

$$
\frac{d M}{d t}=C m \quad\left(C=\frac{1}{\tau}\right)
$$

where $C$ and $\tau$ are a conversion rate and conversion time, respectively. In the diagnostic analysis of the effect of cumulus clouds ensemble on the large-scale structure of the tropical atmosphere, the conversion rate is often assumed to be $0.001 / \mathrm{sec}$ (Yanai et al., 1973; Nitta, 1875) or $0.005 / \mathrm{sec}$ (Ogura and Cho, 1973) for an individual cumulus cloud. These values mean that cloud water is converted into rainwater very efficiently. Sasamori (1975) and Roads (1978) estimated from the study of global hydrologic circulation that the rate was $5 \times 10^{-5}$ to $10^{-4}$ / sec.

In the cloud system of steady state the downward mass flux of rainwater at the bottom of a vertical air column $(R)$ is related to integrated cloud water amount in the column on the basis of eq. (10) as follows:

$$
\begin{aligned}
& \langle R\rangle=C^{\prime}\langle\bar{m}\rangle \\
& \langle R\rangle=\frac{1}{S} \int_{S} R d s \\
& \langle\bar{m}\rangle=\frac{1}{S} \int_{S} \bar{m} d s,
\end{aligned}
$$

$S$ is the horizontal area of the column and $C^{\prime}$ is an averaged conversion rate in the column.

The relationship between integrated cloud water amount derived from ESMR data and rainfall intensity at each station over the AMTEX area is shown in Fig. 14. Rainfall intensities shown in Fig. 14 are values averaged for two hours. Relations (11) for some values of $\tau^{\prime}\left(=1 / C^{\prime}\right)$ are represented by solid lines. If it is desired to obtain the averaged conversion rate in an extended cloud sytsem of non-steady state, the values which were averaged horizontally for a rather long time should be adopted as rainfall intensity as well as integrated cloud water amount. But it is roughly inferred from Fig. 14 that most values of $\tau^{\prime}$ were $2 \times 10^{3}$ to $10^{4} \mathrm{sec}$ and the values of $C^{\prime}$ were $10^{-4}$ to $5 \times 10^{-4} / \mathrm{sec}$ for extended cloud systems over the AMTEX area during the period of cold-air outbreak. These values imply that precipitation formation was not efficient in these cloud systems, though conversion rates were in a considerably wide range. Different values of the rate should be interpretted in association with the structure of the cloud system and the processes of precipitation formation in it. Regrettably we could not discuss this problem for lack of other necessary data. The simultaneously observation of satellite

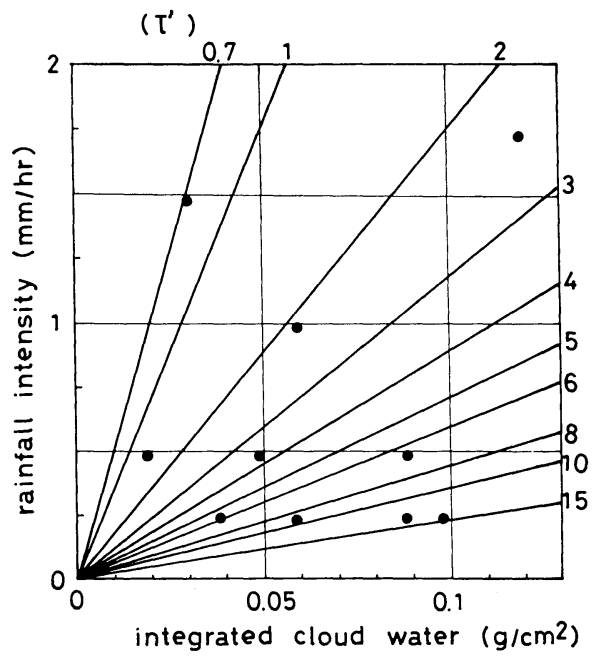

Fig. 14 Relations expressed by eq. (11) for some values of conversion time $\tau^{\prime}$ $\left(\times 13^{3} \mathrm{sec}\right)$. Each black circle shows the relationship between integrated cloud water amount derived from satellite microwave data and averaged rainfall intensity at each station during the period of cold-air outbreak. 
multi-channel radiometers and radars, including aircraft measurements, would be needed so as to make a satisfactory understanding of the conversion rate for an extended cloud system.

\section{Summary}

Our discussion and analysis on the estimation of liquid water amount in an extended cloud are summarized as follows.

(1) Integrated liquid water amount less than $0.30 \mathrm{~g} / \mathrm{cm}^{2}$ can be estimated from satellite microwave data with the error less than $10 \%$ even in consideration of the effect of different size distribution of drops on estimated values. Differences in the vertical profiles of air temperature and liquid water content, and cloud depth hardly influence the estimation of integrated liquid water amount.

(2) Integrated liquid water amounts over the AMTEX area were estimated from Nimbus-5 ESMR data. They were smaller than $0.12 \mathrm{~g} / \mathrm{cm}^{2}$ during the period of cold-air outbreak. Different values of integrated liquid water amount seem to reflect the difference in the type of clouds. Integrated liquid water amount was smaller than $0.03 \mathrm{~g} / \mathrm{cm}^{2}$ in the case of only low-level clouds and it was from 0.05 to $0.12 \mathrm{~g} / \mathrm{cm}^{2}$ in the case of the system composed of low-level clouds and middle-level clouds.

(3) The rate of conversion from cloud water into rainwater was roughly estimated for cloud systems over the AMTEX area during the period of cold-air outbreak. It was from $10^{-4}$ to $5 \times$ $10^{-4} / \mathrm{sec}$. Different values of the conversion rate could not be interpretted for lack of necessary data.

\section{Acknowledgements}

The authors wish to express their hearty thanks to the NASA Goddard Space Flight Center for the supply of Nimbus-5 ESMR data and to Mr. Z. Yanagisawa of Meteorological Research Institute for the supply of data of a $8.6 \mathrm{~mm}$ radar. The authors are also grateful to Dr. K. Okamoto of Radio Research Laboratory and Dr. M. Kano of Meteorological Research Institute for their valuable comments and suggestions. This study was supported by Grant-inAid for Scientific Research, the Ministry of Education, Science and Culture.

\section{References}

Allison, L. J., E. B. Rodgers, T. T. Wilheit and R.
W. Fett, 1974: Tropical cyclone rainfall as measured by the Nimbus-5 Electrically Scanning Microwave Radiometer. Bull. Amer. Meteor. Soc., 55, 1074-1089.

Berry, E. X., 1968: Modification of the warm rain process. Preprints First Nat. Conf. Weather Modification, Albany, Amer. Meteor. Soc., 81-85.

Cotton, W. R., 1970: A numerical simulation of precipitation development in supercooled cumuli. Ph.D. Dissertation, Penn. State Univ., 1-179.

Grody, N. C., A. Gruber and W. C. Shen, 1980: Atmospheric water content over the tropical Pacific derived from the Nimbus-6 Scanning Microwave Spectrometer. J. Appl. Meteor., 19, 986996.

Hollinger, J. P., 1970: Passive microwave measurement of the sea surface. J. Geophys. Res., 75, 5209-5213.

Liou, K. N., 1973: A numerical experiment on Chandrasekar's discrete ordinate method for radiative transfer: Application to cloudy and hazy atmosphere. J. Atmos. Sci., 30, 1303-1326.

Ninomiya, K., 1975: Large-scale aspects of airmass transformation over the East China Sea during AMTEX '74. J. Meteor. Soc. Japan, 53, 285-303.

Nitta, T., 1975: Observational determination of cloud mass flux distributions. J. Atmos. Sci., 32, 73-91.

Nordberg, W., J. Conaway, D. B. Ross and T. T. Wilheit, 1971: Measurements of microwave emission from a foam-covered, wind-driven sea. $J$. Atmos. Sci., 28, 429-435.

Ogura, Y., and H. R. Cho, 1973: Diagnostic determination of cumulus cloud populations from observed large-scale variables. J. Atmos. Sci., 30, 1276-1286.

Ray, P. S., 1972: Broadband complex refractive indices of ice and water. Appl. Optics, 11, 18361844.

Roads, J. O., 1978: Numerical experiments on the climatic sensitivity of an atmospheric hydrologic cycle. J. Atmos. Sci., 35, 753-773.

Rosenkranz, P. W., and D. H. Staelin, 1972: Microwave emissivity of ocean foam and its effect on nadiral radiometric measurements. J. Geophys. Res., 77, 6528-6538.

Sasamori, S., 1975: A statistical model for stationary atmospheric cloudiness, liquid water content, and rate of precipitation. Mon. Wea. Rev., 103, 1037-1049.

Sekhon, R. S., and R. C. Srivastava, 1971: Doppler radar observations of dropsize distributions in a thunderstorm. J. Atmos. Sci., 28, 983-994.

Staelin, D. H., 1966: Measurements and interpretation of the microwave spectrum of the terrestrial atmospheric near $1 \mathrm{~cm}$ wavelength. J. Geophys. Res., 71, 2875-2881. 
Poon, R. W. Wilcox and J. W. Waters, 1976: Remote sensing of atmospheric water vapor and liquid water with the Nimbus-5 microwave spectrometer. J. Appl. Meteor., 15, 1204-1214.

Stogryn, A., 1967: The apparent temperature of the sea at microwave frequencies. I.E.E.E. Trans. Antennas Propagt., 15, 278-286.

Takeda, T., K. Isono, Y. Ishizaka, Y. Iwasaka, M. Wada and Y. Fujiyoshi, 1979: Observational study of precipitation around the Southwest Islands during AMTEX periods in 1974 and 1975. J. Meteor. Soc. Japan, 57, 52-63.

Tsang, L., J. A. Kong, E. Njoku, D. H. Staelin and J. W. Waters, 1977: Theory for microwave thermal emission from a layer of cloud or rain.
I.E.E.E. Trans. Antennas Propagat., 25, 650-657. Warner, J., 1969: The microstructure of cumulus cloud, Part 1. General features of the droplet spectrum. J. Atmos. Sci., 26, 1049-1059.

Wilheit, T. T., 1972: The Electrically Scanning Microwave Radiometer experiment. Nimbus-5 User's Guide, 55-105.

A. T. C. Chang, M. S. V. Rao, E. B. Rodgers and J. S. Theon, 1977: A satellite technique for quantitatively mapping rainfall rates over the oceans. J. Appl. Meteor., 16, 551-560.

Yanai, M., S. Esbensen and J. H. Chu, 1973: Determination of bulk properties of tropical cloud clusters from large-scale heat and moisture budgets. J. Atmos. Sci., 30, 611-627.

\title{
Nimbus-5 マイクロウェーブテータによる 広域雲系の凝結水量の評価
}

\author{
武田喬男・夏 木尚 平* \\ 名古屋大学水圈科学研究所
}

人工衛星のマイクロウェーブ・データから大気中の液体凝結水量を求めることの妥当性を, 数値計算によりま ず検討した後，実際に Nimbus-5 のデータ (ESMR : 19.35 GHz) を用いて AMTEX 領域上の雲系について 液体凝結水量を評価した。数值計算では，水滴の粒径分布の違いおよび他の因子の違いが評価値におよぼす効果 を検討したが，液体凝結水量（鉛直方向に積分したもの）が $0.30 \mathrm{~g} / \mathrm{cm}^{2}$ 程度以下の場合は，水滴の粒径分布の 違いを考慮しても，ほぼ10\% 以内の誤差で凝結水量を評価することが出来ることが示された。1974 年 AMTEX 期間中の寒気吹き出し（2 月 25 日から 27 日）の AMTEX 領域上の凝結水量は， $0.12 \mathrm{~g} / \mathrm{cm}^{2}$ 以下であると評価 された。評価值は雲系により異なり，下層雲のみで構成されている雲系では $0.03 \mathrm{~g} / \mathrm{cm}^{2}$ 以下であり，下層雲と 中層雲で構成されていた二層の雲系では $0.05 \sim 0.12 \mathrm{~g} / \mathrm{cm}^{2}$ であったこれらの凝結水量と地上の降水強度を用 いて，雲水が降水に変換していく速さを評価することを試みた。 